\title{
Evaluation of fontanel size variation and closure time in children followed up from birth to 24 months
}

\author{
Perran Boran, MD, PhD, ${ }^{1}$ Fatma Oğuz, MD, ${ }^{2}$ Andrzej Furman, PhD, ${ }^{3}$ and Sibel Sakarya, MD, MSc ${ }^{4}$ \\ 'Department of Pediatrics, Marmara University, School of Medicine; ${ }^{2}$ Institute of Child Health, Istanbul University; ${ }^{3}$ nstitute \\ of Environmental Sciences, Bogazici University; and ${ }^{4}$ Department of Public Health, Marmara University, School of Medicine, \\ Istanbul, Turkey
}

OBJECTIVE Anterior fontanel size and closure time can be useful clinical signs for the early diagnosis of diseases. Knowing age-related normal variations is important to decide on further investigations. The authors of this study aimed to describe fontanel size variation according to age, determine fontanel closure time, and identify the optimal method for assessing fontanel size.

METHODS For this prospective cohort study, 321 healthy term babies who fulfilled the inclusion criteria were consecutively recruited. Percentile charts for the mean anterior fontanel size and oblique measurements from birth to 24 months of age were created.

RESULTS The mean fontanel closure time was $9.7 \pm 5.0$ months (girls $10.3 \pm 4.7$ months, boys $9.2 \pm 5.1$ months). No differences were observed between the traditional method and oblique measurements. Early fontanel closure was not associated with microcephaly.

CONCLUSIONS Oblique measurements can be used because they are as accurate as the traditional method. Children with fontanels measuring above the 95th percentile should be monitored closely and investigated further for potentially associated diseases.

https://thejns.org/doi/abs/10.3171/2018.3.PEDS17675

KEYWORDS anterior fontanel; anthropometry; child; infant; physical examination; diagnostic technique

$\mathrm{T}$ HE size of the anterior fontanel is assessed by measuring head circumference and is generally accepted to be an index of cranial development and osseous maturation. ${ }^{3,13}$ The anterior fontanel at birth varies in size, usually ranging from 1 to $3 \mathrm{~cm}$. The age at which anterior fontanel closure occurs ranges between 10 and 24 months. The anterior fontanel size and closure time are considered to be useful clinical signs for the early diagnosis of diseases. For instance, a large fontanel and/or delayed closure can indicate hypothyroidism and skeletal disorders such as rickets, cleidocranial dysostosis, and increased cranial pressure. ${ }^{3,13}$ In contrast, a small fontanel and early closure can indicate hyperthyroidism, disorders that affect brain growth such as microcephaly and craniosynostosis, and other conditions.,13 Thus, knowing age-related normal variations is important to decide on further investigations.
In 2007, the World Health Organization (WHO) released growth charts that suggested that unconstrained growth of economically advantaged, breastfed infants and children does not substantially vary and that a single set of growth curves can describe a human physiological norm up to 5 years of age. ${ }^{29}$ However, the meta-analysis by Natale and Rajagopalan showed that the head size in breastfed children examined at any age was far closer to local norms than to the Multicentre Growth Reference Study mean head size. ${ }^{18}$ Furthermore, considerable differences in head circumference exist between WHO charts and national or ethnic groups, which could put many children at risk for misdiagnosis of macrocephaly or microcephaly. ${ }^{18}$

Racial and ethnic differences in fontanel size have also been identified, and local references should be used for evaluating the fontanel size of infants from different 
populations. Furthermore, most previous studies were conducted in newborns, and only cross-sectional studies and limited data have been published regarding fontanel dimensions related to age during the first 2 years of life., ${ }^{1,2}$ 4,5,7,9,10,12,14-17,19-24,26,27,31 Three studies with a longitudinal design were published more than 2 decades ago, and one of these studies included only 33 infants., , $20,23^{2}$

In this study, we primarily aimed to describe the range of fontanel size variation according to age and to determine fontanel closure time over the course of the first 2 years of life in healthy infants. Our secondary aim was to identify an optimal method for assessing fontanel size.

\section{Methods}

This longitudinal study comprised the birth cohort of infants who visited the Marmara University's well-child outpatient clinic. Since 2010, the Marmara University Hospital has been operating under the name of the Ministry of Health Marmara University Pendik Research and Training Hospital in Pendik. Istanbul is the largest city in Turkey, and Pendik, located in the eastern part of Istanbul, is the city's fifth most crowded district, having a population of 646,375 . The fontanel data obtained were those of newborns born at the maternity clinic of the university hospital between May 2013 and May 2014 and patients visiting the well-child outpatient clinic. Mothers who gave birth at the university hospital's maternity clinic received a pamphlet with information regarding how to make an appointment at the well-child outpatient clinic. Mothers of the newborns were invited to participate in the study. Each newborn is generally scheduled for a first appointment at 2 weeks of age and is then followed up on a monthly basis for the first 6 months, at 3-month intervals until 18 months of age, and then every 6 months thereafter up to 5 years of age. The infants were followed up monthly for the first year of life for this study. Physical examinations, growth and developmental surveillance, immunizations, and anticipatory guidance were provided during the visits. Data regarding anthropometry, motor development, feeding practices, perinatal factors, and sociodemographic characteristics were recorded in individual personal files. Inclusion criteria included infants of nonsmoking mothers, a gestational age $\geq 37$ completed weeks, the absence of any neonatal or postnatal medical condition, and maternal willingness to enter the study. Premature infants, infants small for their gestational age, and infants with congenital anomalies were excluded. In total, 400 healthy term newborns who fulfilled the inclusion criteria were consecutively enrolled in the longitudinal sample. Of the 400 newborns, 56 were excluded because they did not complete the 24-month follow-up and 23 were excluded because measurements for more than two visits were missing. Finally, 321 babies were included in the analysis. Socioeconomic status was evaluated on the basis of data collected regarding properties owned by the household, heating sources, household incomes, educational years, and working statuses of the parents. ${ }^{6,25}$ Most parents had a middle or high socioeconomic status ( $53 \%$ and $45 \%$, respectively). The mean age of the mothers was $28.9 \pm 4.9$ years, and they had a mean of $8.3 \pm 3.7$ years of education. Approximately
$79 \%$ of the infants were exclusively breastfed for 4 months and $50 \%$ for 6 months.

The sample chosen for determining reference intervals should reflect the overall healthy population and the population at large. Worldwide, the growth patterns of children are probably similar when their health and care requirements are met. The sample chosen for this study included infants who were well nourished and mostly breastfed and who lived in socioeconomic conditions that were favorable to growth. All mothers were nonsmokers before and after delivery. The construction of fontanel size curves followed a careful, methodical process. We used a longitudinal design. The results enabled us in extrapolating the results to the national level. For all these demographic, geographic, and socioeconomic reasons, we considered the population to be representative of the entire Turkish population.

Longitudinal, transverse, and oblique dimensions of the anterior fontanel, along with weight, length, and occipitofrontal circumferences, were measured at the age of 2 weeks, at monthly intervals during the first year, and every 3 months until the age of 2 years. The measurements were recorded to the nearest millimeter. Using a narrow nonstretchable tape calibrated in millimeters that was placed around the child's head, crossing the forehead superior to the supraorbital ridges and the prominence of the occiput at the back, we measured the head circumference. The occipitofrontal circumference of the parents of children diagnosed with micro- or macrocephaly was measured and then converted to standard scores. ${ }^{28}$ The parental standardized values were then averaged and plotted using the Weaver curve. ${ }^{28}$ The supine length was measured using an infantometer; naked weights were measured using an electronic digital scale that had an accuracy of $0.01 \mathrm{~kg}$.

To determine the fontanel size, we used the technique described by Popich and Smith. ${ }^{23}$ Measurements were performed by two trained nurses, with each nurse measuring twice. Interexaminer agreement was analyzed using kappa statistics, and a high degree of agreement was observed between the two examiners (kappa index 89.7\%). The index finger of the examiner was placed on each corner of the fontanel, and with a washable pencil, a small dot was marked on the scalp near the fingertip (Fig. 1). The anteroposterior diameter (AB) was determined as the length, transverse diameter (CD) as the width, and oblique diameter $(\mathrm{EF})$ as the distance between the points. The fingertips were placed at the points that corresponded to the estimated midpoints of the edges of the frontal and parietal bones; these points provided the boundaries of the fontanel to obtain the oblique diameter. The average of the longitudinal and transverse dimensions was recorded as the mean fontanel size $([\mathrm{AB}+\mathrm{CD}] / 2)$, and the average of the oblique diameters was recorded as the oblique dimension. A fontanel that was too small to be measured was considered closed. . $^{146,23}$

Statistical analyses were performed using SPSS software version 16 (SPSS Inc.). Using visual and analytical methods, we investigated the variables to determine whether they were normally distributed. Descriptive analyses were presented using the mean \pm standard deviation for normally distributed variables and medians and percentiles for nonnormally distributed or ordinal variables. 


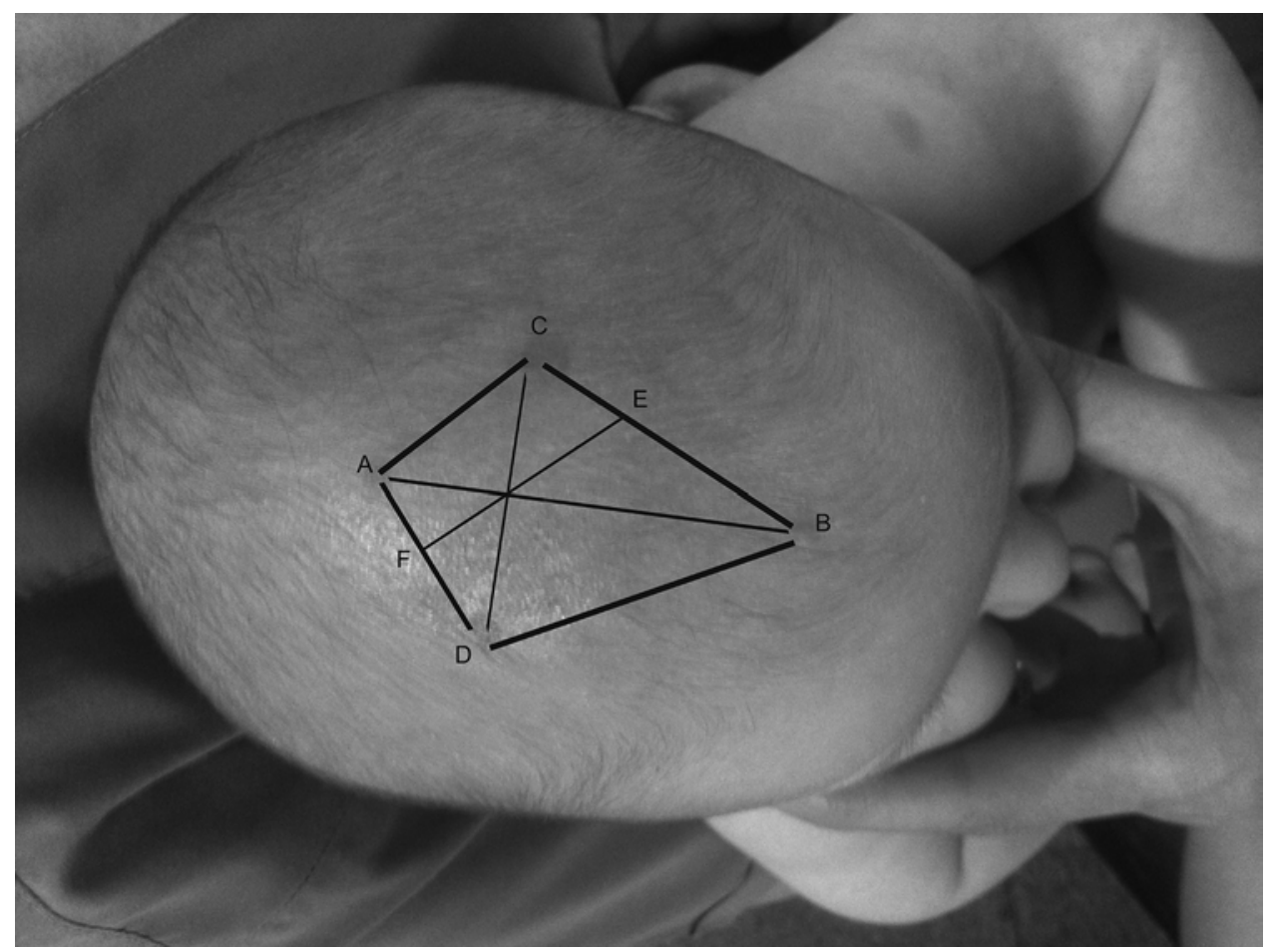

FIG. 1. Measurement points of the anterior fontanel. The anteroposterior diameter $(A B)$ was determined as the length, transverse diameter (CD) as the width, and oblique diameter (EF) as the distance between the points.

Pearson correlation statistics was used to determine the association between fontanel measurements. Percentiles for the fontanel size were calculated using bootstrapping.

Variables putatively associated with fontanel closure time were investigated using general linear models. Binary logistic regression analysis was performed to assess the probability of fontanel closure as a function of age and of sex. The percentile data derived from bootstrapping, which represented fontanel size as a function of time, were approximated on the graphs using regression lines. The percentile data of the fontanel size of children whose fontanels were still open were approximated on the graphs using the Epanechnikov kernel function. A p value $<0.05$ was regarded as statistically significant.

Parents provided written and verbal informed consent for all the enrolled infants, in accordance with the local ethics committee (Marmara University, School of Medicine, Istanbul, Turkey), which reviewed and approved the study protocol.

\section{Results \\ Study Sample}

The mean weight, length, and head circumference of the 321 newborns (179 boys and 142 girls) analyzed in our study were $3339 \pm 350 \mathrm{~g}, 50 \pm 1.9 \mathrm{~cm}$, and $34.7 \pm 1.2 \mathrm{~cm}$, respectively. The mean anterior fontanel size was $2.9 \pm$ $0.9 \mathrm{~cm}$; the fontanel size did not correlate with any of the birth measurements. Regarding weight, length, and head circumference, all infants, except 10 , had values within the normal ranges on the WHO growth charts. After the age of 6 months, microcephaly was diagnosed in six infants and macrocephaly in four. None of the infants showed any neurodevelopmental delay.

\section{Fontanel Size}

For all age groups, the mean fontanel size and oblique diameter measurements were highly correlated with each other; the correlation coefficients varied from 0.797 at 1 month to 0.908 at 3 months (all p < 0.001). The correlation analyses did not include children whose fontanels were already closed. The number of closed fontanels rapidly increases with age in children, which poses a problem for constructing age charts for a typical fontanel size variation. Including closed fontanels shifts the size distribution toward zero, making a parametric approach uninformative. As an alternative, we bootstrapped the fontanel size data of all children in each age group (1000 times) and presented the data directly derived from simulated sets rather than from parametric statistics (Tables 1 and 2).

The transverse diameter was significantly higher than the longitudinal diameter for all age groups except the newborn group. After eliminating data for children with closed fontanels, we presented the distribution of fontanel size in children whose fontanels were not closed (Tables 3 and 4 and Figs. 2 and 3).

\section{Closure Time}

The mean patient age at fontanel closure was $9.7 \pm 5.0$ months; the median was 9 months, and the 25 th and 75 th quartiles were 6 and 12 months, respectively. Fontanels tended to close earlier in boys than in girls $(9.2 \pm 5.1$ and $10.3 \pm 4.7$ months, respectively); however, the difference 
TABLE 1. Mean fontanel size (in $\mathrm{cm}$ ) derived from bootstrapping

\begin{tabular}{|c|c|c|c|c|c|c|c|c|c|}
\hline \multirow[b]{2}{*}{ Age } & \multicolumn{9}{|c|}{ Percentile } \\
\hline & $3 r d$ & 5 th & 10th & 25th & 50th & 75th & 90th & 95th & 97th \\
\hline 15 days & 1.00 & 1.36 & 1.80 & 2.35 & 3.00 & 3.50 & 4.00 & 4.25 & 4.58 \\
\hline $1 \mathrm{mo}$ & 0.00 & 1.00 & 1.66 & 2.20 & 2.75 & 3.38 & 3.80 & 4.00 & 4.50 \\
\hline $2 \mathrm{mos}$ & 0.00 & 0.00 & 1.26 & 1.91 & 2.42 & 3.00 & 3.50 & 3.95 & 4.00 \\
\hline $3 \mathrm{mos}$ & 0.00 & 0.00 & 0.00 & 1.55 & 2.15 & 2.73 & 3.13 & 3.45 & 4.00 \\
\hline 4 mos & 0.00 & 0.00 & 0.00 & 1.06 & 2.00 & 2.50 & 3.00 & 3.30 & 3.50 \\
\hline $5 \mathrm{mos}$ & 0.00 & 0.00 & 0.00 & 0.00 & 1.75 & 2.25 & 2.84 & 3.35 & 3.50 \\
\hline $6 \mathrm{mos}$ & 0.00 & 0.00 & 0.00 & 0.00 & 1.50 & 2.00 & 2.65 & 3.05 & 3.46 \\
\hline $9 \mathrm{mos}$ & 0.00 & 0.00 & 0.00 & 0.00 & 0.00 & 1.50 & 2.00 & 2.49 & 2.62 \\
\hline $12 \mathrm{mos}$ & 0.00 & 0.00 & 0.00 & 0.00 & 0.00 & 0.00 & 1.60 & 1.80 & 2.21 \\
\hline $15 \mathrm{mos}$ & 0.00 & 0.00 & 0.00 & 0.00 & 0.00 & 0.00 & 0.00 & 1.50 & 1.54 \\
\hline $18 \mathrm{mos}$ & 0.00 & 0.00 & 0.00 & 0.00 & 0.00 & 0.00 & 0.00 & 0.00 & 0.00 \\
\hline $24 \mathrm{mos}$ & 0.00 & 0.00 & 0.00 & 0.00 & 0.00 & 0.00 & 0.00 & 0.00 & 0.00 \\
\hline
\end{tabular}

was only borderline significant $(\mathrm{p}=0.06)$. Fontanels were closed in approximately $11 \%$ of the children at the age of 3 months, in $32 \%$ at 6 months, in $56 \%$ at 9 months, in $81 \%$ at 12 months, and in $96 \%$ at 18 months. By the age of 24 months, fontanels had closed in all of the children. Binary logistic regression models were used to assess the age at which fontanels had closed in 50\% of the children: 7.7 months for boys and 8.9 months for girls $(8.3$ months for the pooled data). The sex variable was significant at $p$ values $<0.001$.

Fontanel closure time was associated with the mean fontanel size and oblique measurements at birth $(\mathrm{r}=0.570$ and 0.527 , respectively; both $\mathrm{p}<0.001$ ). Fontanel closure time can be approximately calculated $\left(\mathrm{R}^{2}=0.45\right)$ from the mean fontanel size and oblique fontanel dimension at the age of 1 month: fontanel closure time $=[2.1 \times($ mean fontanel size $)]+[2.3 \times($ oblique fontanel dimension $)]-$ 0.705 .

TABLE 2. Oblique fontanel size (in $\mathrm{cm}$ ) derived from bootstrapping

\begin{tabular}{lrrrrrrrrr}
\hline & \multicolumn{10}{c}{ Age } & 3rd & 5 th & 10 th & 25th & 50 th & 75 th & 90 th & 95 th & 97 th \\
\hline 15 days & 0.50 & 1.00 & 1.11 & 1.50 & 2.00 & 2.50 & 3.00 & 3.00 & 3.22 \\
\hline 1 mo & 0.00 & 1.00 & 1.00 & 1.50 & 2.00 & 2.20 & 2.89 & 3.00 & 3.30 \\
\hline 2 mos & 0.00 & 0.00 & 1.00 & 1.22 & 1.70 & 2.00 & 2.50 & 3.00 & 3.00 \\
\hline 3 mos & 0.00 & 0.00 & 0.00 & 1.00 & 1.50 & 2.00 & 2.20 & 2.59 & 3.00 \\
\hline 4 mos & 0.00 & 0.00 & 0.00 & 0.80 & 1.50 & 1.80 & 2.09 & 2.50 & 2.67 \\
\hline 5 mos & 0.00 & 0.00 & 0.00 & 0.00 & 1.20 & 1.50 & 2.00 & 2.40 & 2.50 \\
\hline 6 mos & 0.00 & 0.00 & 0.00 & 0.00 & 1.00 & 1.50 & 2.00 & 2.19 & 2.32 \\
\hline 9 mos & 0.00 & 0.00 & 0.00 & 0.00 & 0.00 & 1.00 & 1.50 & 1.99 & 2.00 \\
\hline 12 mos & 0.00 & 0.00 & 0.00 & 0.00 & 0.00 & 0.00 & 1.00 & 1.50 & 1.70 \\
\hline 15 mos & 0.00 & 0.00 & 0.00 & 0.00 & 0.00 & 0.00 & 0.00 & 1.00 & 1.00 \\
\hline 18 mos & 0.00 & 0.00 & 0.00 & 0.00 & 0.00 & 0.00 & 0.00 & 0.00 & 0.00 \\
\hline 24 mos & 0.00 & 0.00 & 0.00 & 0.00 & 0.00 & 0.00 & 0.00 & 0.00 & 0.00 \\
\hline
\end{tabular}

TABLE 3. Mean fontanel size (in $\mathrm{cm}$ ) in children whose fontanels were still open

\begin{tabular}{|c|c|c|c|c|c|c|c|c|c|}
\hline \multirow[b]{2}{*}{ Age } & \multicolumn{9}{|c|}{ ercentile } \\
\hline & 3rd & 5th & 10th & 25th & 50th & 75th & 90th & 95th & 97th \\
\hline 15 days & 1.34 & & 1.87 & 2.41 & 3.01 & 3.60 & 4.14 & 4.46 & 4.67 \\
\hline $1 \mathrm{mo}$ & 1.24 & 1.44 & 1.74 & 2.24 & 2.80 & 3.36 & 3.86 & 4.16 & 4.36 \\
\hline $2 \mathrm{mos}$ & 1.15 & 1.33 & 1.61 & 2.08 & 2.60 & 3.12 & 3.59 & 3.87 & 4.05 \\
\hline $3 \mathrm{mos}$ & 1.07 & 1.24 & 1.50 & 1.94 & 2.42 & 2.91 & 3.35 & 3.61 & 3.78 \\
\hline $4 \mathrm{mo}$ & 1.00 & 1.16 & 1.41 & 1.82 & 2.28 & 2.74 & 3.15 & 3.40 & 3.56 \\
\hline $5 \mathrm{mos}$ & 0.95 & 1.10 & 1.34 & 1.73 & 2.17 & 2.61 & 3.00 & 3.24 & 3.39 \\
\hline $6 \mathrm{mos}$ & 0.91 & 1.05 & 1.28 & 1.65 & 2.07 & 2.49 & 2.87 & 3.09 & 3.24 \\
\hline $7 \mathrm{mos}$ & 0.86 & 1.00 & 1.22 & 1.58 & 1.98 & 2.38 & 2.74 & 2.96 & 3.10 \\
\hline $8 \mathrm{mos}$ & 0.83 & 0.96 & 1.17 & 1.51 & 1.90 & 2.28 & 2.63 & 2.84 & 2.97 \\
\hline $9 \mathrm{mos}$ & 0.79 & 0.92 & 1.12 & 1.46 & 1.83 & 2.20 & 2.53 & 2.73 & 2.86 \\
\hline $10 \mathrm{mc}$ & 0.77 & 0.89 & 1.09 & 1.41 & 1.77 & 2.13 & 2.45 & 2.64 & 2.77 \\
\hline $11 \mathrm{mo}$ & 0.74 & 0.87 & 1.05 & 1.37 & 1.72 & 2.07 & 2.38 & 2.57 & 2.69 \\
\hline $12 \mathrm{mo}$ & 0.72 & 0.84 & 1.03 & 1.33 & 1.67 & 2.01 & 2.32 & 2.50 & 2.62 \\
\hline $13 \mathrm{mo}$ & 0.70 & 0.82 & 1.00 & 1.30 & 1.63 & 1.96 & 2.25 & 2.43 & 2.55 \\
\hline $14 \mathrm{mo}$ & 0.68 & 0.80 & 0.97 & 1.26 & 1.58 & 1.90 & 2.19 & 2.37 & 2.48 \\
\hline $15 \mathrm{mos}$ & 0.66 & 0.77 & 0.94 & 1.22 & 1.54 & 1.85 & 2.13 & 2.30 & 2.41 \\
\hline $16 \mathrm{mo}$ & 0.65 & 0.75 & 0.92 & 1.19 & 1.50 & 1.80 & 2.08 & 2.24 & 2.35 \\
\hline $17 \mathrm{mo}$ & 0.63 & 0.73 & 0.89 & 1.16 & 1.46 & 1.76 & 2.03 & 2.19 & 2.29 \\
\hline $18 \mathrm{mos}$ & 0.61 & 0.72 & 0.87 & 1.13 & 1.42 & 1.72 & 1.98 & 2.13 & 2.24 \\
\hline
\end{tabular}

\section{Discussion}

The period of improved socioeconomic conditions, nutrition, and health practices in developed countries was, until recently, accompanied by concomitant changes in human growth and maturation. ${ }^{11}$ Thus, many growth reference values have changed and are in urgent need of updating. Here, we focused on developing fontanel growth reference charts that can be used by pediatricians in Turkey and possibly in other countries. We constructed percentile charts for the mean anterior fontanel and oblique measurement size changes in children up to 24 months of age. We also provided data regarding fontanel closure time. In this study, we followed the WHO criteria for establishing growth charts, which allows for the generalization of our results.

Following up a large cohort of newborns for approximately the first 2 years of life allowed us to determine the exact fontanel closure time in each child. Then, we could compute a mean and standard deviation of the sample. Another possible approach would be to use a segment sampling and construct a binary logistic regression model. Here, the data included only information about the age of a child and the fontanel status (open or closed). The results could be reported as the age at which the fontanel closed in 50\% of the children. This model also provided the probability of fontanel closure for any age. Ideally, for normally distributed data, the mean value for the cohort study should be about the same as the median value for the segment study (9.7 and 8.3 months, respectively). In our study group, fontanels closed in 50\% of children at the 
TABLE 4. Oblique fontanel size (in $\mathrm{cm}$ ) in children whose fontanels were still open

\begin{tabular}{|c|c|c|c|c|c|c|c|c|c|}
\hline \multirow[b]{2}{*}{ Age } & \multicolumn{9}{|c|}{ Percentile } \\
\hline & $3 r d$ & 5th & 10th & 25th & 50th & 75th & 90th & 95th & 97th \\
\hline 15 days & 0.82 & 0.97 & 1.22 & 1.62 & 2.07 & 2.52 & 2.92 & 3.16 & 3.32 \\
\hline $1 \mathrm{mo}$ & 0.76 & 0.91 & 1.14 & 1.53 & 1.95 & 2.38 & 2.76 & 2.99 & 3.14 \\
\hline 2 mos & 0.71 & 0.85 & 1.07 & 1.43 & 1.84 & 2.24 & 2.60 & 2.82 & 2.96 \\
\hline $3 \mathrm{mos}$ & 0.66 & 0.79 & 1.00 & 1.35 & 1.73 & 2.11 & 2.46 & 2.66 & 2.80 \\
\hline $4 \mathrm{mos}$ & 0.62 & 0.74 & 0.94 & 1.27 & 1.63 & 1.99 & 2.32 & 2.52 & 2.65 \\
\hline $5 \mathrm{mos}$ & 0.57 & 0.70 & 0.88 & 1.19 & 1.54 & 1.89 & 2.20 & 2.38 & 2.50 \\
\hline $6 \mathrm{mos}$ & 0.54 & 0.65 & 0.83 & 1.13 & 1.46 & 1.79 & 2.08 & 2.26 & 2.37 \\
\hline $7 \mathrm{mos}$ & 0.50 & 0.61 & 0.78 & 1.07 & 1.38 & 1.70 & 1.98 & 2.15 & 2.26 \\
\hline $8 \mathrm{mos}$ & 0.48 & 0.58 & 0.75 & 1.02 & 1.32 & 1.62 & 1.89 & 2.06 & 2.16 \\
\hline $9 \mathrm{mos}$ & 0.45 & 0.56 & 0.71 & 0.98 & 1.27 & 1.56 & 1.83 & 1.98 & 2.09 \\
\hline $10 \mathrm{mc}$ & 0.44 & 0.54 & 0.69 & 0.95 & 1.23 & 1.52 & 1.78 & 1.93 & 2.03 \\
\hline $11 \mathrm{mo}$ & 0.42 & 0.52 & 0.67 & 0.93 & 1.21 & 1.49 & 1.74 & 1.89 & 1.99 \\
\hline $12 \mathrm{mo}$ & 0.41 & 0.51 & 0.66 & 0.91 & 1.18 & 1.46 & 1.71 & 1.86 & 1.95 \\
\hline $13 \mathrm{mo}$ & 0.40 & 0.49 & 0.64 & 0.89 & 1.16 & 1.43 & 1.68 & 1.83 & 1.92 \\
\hline $14 \mathrm{mo}$ & 0.39 & 0.48 & 0.63 & 0.87 & 1.14 & 1.41 & 1.65 & 1.79 & 1.89 \\
\hline $15 \mathrm{mos}$ & 0.38 & 0.47 & 0.61 & 0.85 & 1.12 & 1.38 & 1.62 & 1.76 & 1.86 \\
\hline $16 \mathrm{mc}$ & 0.37 & 0.46 & 0.60 & 0.83 & 1.10 & 1.36 & 1.59 & 1.73 & 1.83 \\
\hline $17 \mathrm{mo}$ & 0.36 & 0.45 & 0.59 & 0.82 & 1.08 & 1.34 & 1.57 & 1.71 & 1.80 \\
\hline $18 \mathrm{mos}$ & 0.35 & 0.44 & 0.57 & 0.80 & 1.06 & 1.31 & 1.54 & 1.68 & 1.77 \\
\hline
\end{tabular}

age of approximately 9 months and in all children by the age of 24 months.

The fontanel closure age in our study is considerably earlier than that in previous studies, in which many children had their fontanels still open at the age of 2 years.,10,20 One of the factors responsible for the late fontanel closure in the previous studies might be vitamin D deficiency, ${ }^{30}$ as evidenced by the high incidence of rickets reported at that time. ${ }^{9,14,16}$ Delayed fontanel closure can also be associated with a low socioeconomic status and undernutrition of children. ${ }^{16}$ Unlike in previous studies, the children in our cohort were healthy, had adequate nutrition, had vitamin D supplementation, and most were from families with a middle or high socioeconomic status. Other sources of differences could be based on the definition of fontanel closure. We considered the fontanel closed if it was too small to be precisely measured, which may not be the case in the previous studies. ${ }^{14,16,23}$ As compared with other studies, $, 14,16$ our study reported higher percentages of closed fontanels at the age of 3 months, and at the age of 1 year, the percentages were similar to those reported in a recent Iranian study. ${ }^{10}$

There was only a small difference in the fontanel closure time between boys and girls. Fontanels were closed approximately 1 month earlier in boys than in girls, but such a difference was clinically irrelevant. Duc and Largo also found that boys tended to have higher percentages of closed fontanels than girls, although the differences were not statistically significant. ${ }^{9}$ Similar results were reported in other studies. $17,15,16,19,20,22,23$ Although the reason we observed a difference in sex regarding the fontanel closure

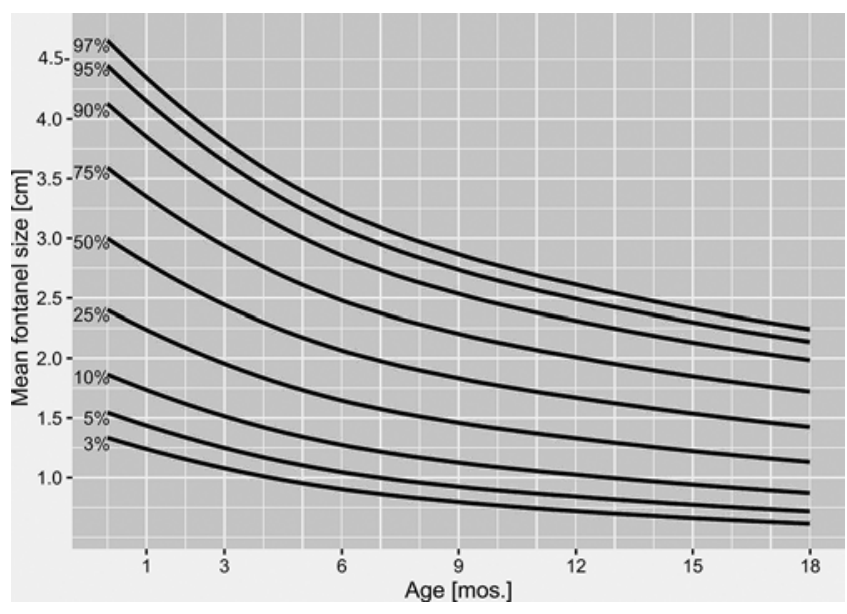

FIG. 2. The percentile curves for mean fontanel size constructed for children whose fontanels were still open. The curves were smoothed by the Epanechnikov kernel function.

time goes beyond the scope of this article, our finding may be explained by differences in brain structure maturation with respect to sex. Because it is known that girls are more skeletally mature than boys from birth onwards and that adverse environmental circumstances affect the growth of males relatively more than females, earlier closure of the fontanel in males reflecting skeletal maturity cannot be explained by osteogenesis. ${ }^{8}$ However, future studies addressing this question and investigating relations between fontanel closure time and sex are required.

Fontanel closure is a terminal event, so we may find it instructive to follow the dynamics of size changes. As time passes, the fontanels of some children closed; therefore, we had two options in presenting the results. If we wished to utilize all the data, we could bootstrap the sample and directly derive nonparametric percentiles from the simulated data sets. We could not use parametric statistics because a closed fontanel (size zero) was not a fontanel

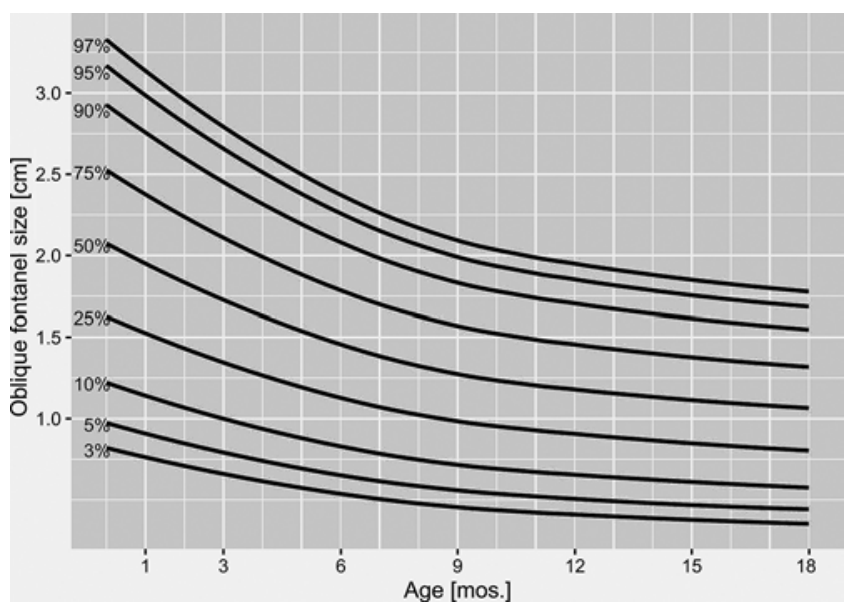

FIG. 3. The percentile curves for oblique fontanel size constructed for children whose fontanels were still open. The curves were smoothed by the Epanechnikov kernel function. 
anymore. However, information regarding the distribution of fontanel size of the children whose fontanels were not closed could be useful. To do that, in each age group, we could eliminate children with closed fontanels and use parametric statistics to compute the percentiles. Those results would have to be well understood and treated with care because the meaning of the percentiles changes with age. After approximately 10 months of age, the percentiles show a distribution of less typical cases, but they may be very useful in a clinical practice.

The most commonly used method of fontanel size measurement is that of Popich, which allows comparison with studies conducted by other researchers. ${ }^{23}$ In contrast, Duc and Largo recommended using oblique measurements because the edges of the frontal and parietal bones are easier to define using fingertips than fontanel corners. ${ }^{9}$ A clear determination of the point at which the fontanel ends and the sutures begin can be difficult, leading to measurement inaccuracies. ${ }^{12}$ Hence, we used oblique measurements in addition to the traditional method. We found no difference between the traditional method and oblique measurements, which is similar to the results of Jackson et al. ${ }^{12} \mathrm{We}$ suggest performing oblique measurements without using a caliper because that method is simpler and accurate.

Fontanel size can increase during the first 2 months of life; ;,20,22,23 however, we did not observe such a trend in our cohort, similar to the reports of other researchers., ${ }^{4,1416}$ Most studies that detected enlargement of the fontanel during the first 2 months of life assessed the fontanel size within 1-2 days of life when the molding of the skull had not yet resolved.

We did not observe negative effects on neurodevelopment in any of the 321 children whose fontanels closed during the first 3 months of age. Three children developed microcephaly, and another three children developed macrocephaly, which is in agreement with the suggestion of Duc and Largo that early closure of the fontanel did not necessarily result in microcephaly. ${ }^{9}$ If the head size, shape, and growth rate are normal in a child with normal neurodevelopmental characteristics, a small and/or closed fontanel should raise no concern. We decided to select the 97th percentile, but perhaps to be on the safe side, we should suggest a closer investigation of children with fontanels measuring above the 95th percentile. Children with fontanels measuring above the 95th percentile should be monitored closely and investigated further for potentially associated diseases such as rickets, hypothyroidism, and increased cranial pressure.

Approximately half of the normal variation in head size can be familial. Although Weaver and Christian detected no significant maternal influence on the child's head size, we found that the mothers of four children diagnosed with microcephaly were also microcephalic and that fathers of children diagnosed with macrocephaly were also macrocephalic. ${ }^{28}$ We concluded that although the number of cases in this study was small, paternal and maternal influences on micro- and macrocephaly should be further investigated in larger samples.

\section{Conclusions}

In summary, the percentile charts generated in this study allow us to decide which case warrants further evaluation, preventing unnecessary diagnostic tests. Oblique measures can be used instead of mean fontanel measurements. Children with fontanels measuring above the 95th percentile should be monitored closely and investigated further for potentially associated diseases. Early closure of the fontanel in children is not rare, and it does not necessarily result in microcephaly. Close follow-up is required, as is paying attention to head circumference, head shape, and neurodevelopment.

\section{Acknowledgments}

We thank the staff nurses for their valuable contributions to this study.

\section{References}

1. Acheson RM, Jefferson E: Some observations on the closure of the anterior fontanelle. Arch Dis Child 29:196-198, 1954

2. Adeyemo AA, Olowu JA, Omotade OO: Fontanelle sizes in term neonates in Ibadan, Nigeria. West Afr J Med 18:55-59, 1999

3. Amiel-Tison C, Gosselin J, Infante-Rivard C: Head growth and cranial assessment at neurological examination in infancy. Dev Med Child Neurol 44:643-648, 2002

4. Ayata A, Öktem F, Çetin H, Özeren G, Örmeci AR: Anterior fontanelle size and closure time. Turk Arch Pediatr 34:7073, 1999

5. Brandt I, Hodes DT, Reimnitz P: [Anterior fontanelle as a window to the brain--normal values and timing of closure.] Klin Padiatr 198:330-336, 1986 (Ger)

6. Braveman PA, Cubbin C, Egerter S, Chideya S, Marchi KS, Metzler M, et al: Socioeconomic status in health research: one size does not fit all. JAMA 294:2879-2888, 2005

7. Chang BF, Hung KL: [Measurements of anterior fontanels in Chinese.] Zhonghua Min Guo Xiao Er Ke Yi Xue Hui Za Zhi 31:307-312, 1990 (Chinese)

8. Cole TJ, Rousham EK, Hawley NL, Cameron N, Norris SA, Pettifor JM: Ethnic and sex differences in skeletal maturation among the birth to twenty cohort in South Africa. Arch Dis Child 100:138-143, 2015

9. Duc G, Largo RH: Anterior fontanel: size and closure in term and preterm infants. Pediatrics 78:904-908, 1986

10. Esmaeili M, Esmaeili M, Ghane Sharbaf F, Bokharaie S: Fontanel size from birth to 24 months of age in Iranian children. Iran J Child Neurol 9:15-23, 2015

11. Hauspie RC, Vercauteren M, Susanne C: Secular changes in growth and maturation: an update. Acta Paediatr Suppl 423:20-27, 1997

12. Jackson GL, Hoyer A, Longenecker L, Engle WD: Anterior fontanel size in term and late preterm Hispanic neonates: description of normative values and an alternative measurement method. Am J Perinatol 27:307-312, 2010

13. Kiesler J, Ricer R: The abnormal fontanel. Am Fam Physician 67:2547-2552, 2003

14. Lyall H, Ogston SA, Paterson CR: Anterior fontanelle size in Scottish infants. Scott Med J 36:20-22, 1991

15. Malas MA, Ataş E: [Determination of anterior fontanel and cranium morphology of premature and full term newborns according to age and sex, and investigation of the relation between them.] S Ü Tip Fak Derg 16:71-77, 2000 (Turkish)

16. Mathur S, Kumar R, Mathur GP, Singh VK, Gupta V, Tripathi VN: Anterior fontanel size. Indian Pediatr 31:161-164, 1994

17. Mir NA, Weislaw R: Anterior fontanelle size in Arab children: standards for appropriately grown full term neonates. Ann Trop Paediatr 8:184-186, 1988 
18. Natale V, Rajagopalan A: Worldwide variation in human growth and the World Health Organization growth standards: a systematic review. BMJ Open 4:e003735, 2014

19. Omotade OO, Kayode CM, Adeyemo AA: Anterior fontanelle size in Nigerian children. Ann Trop Paediatr 15:8991, 1995

20. Pedroso FS, Rotta N, Quintal A, Giordani G: Evolution of anterior fontanel size in normal infants in the first year of life. J Child Neurol 23:1419-1423, 2008

21. Perera PJ, Wickramasinghe AR, Ranathunga N, Fernanado MP, Warnakulasooriya D: Statistical characteristics of anterior fontanelle size at birth of term Sri Lankan new borns: a descriptive cross sectional study. Ceylon Med J 58:96-100, 2013

22. Pindrik J, Ye X, Ji BG, Pendleton C, Ahn ES: Anterior fontanelle closure and size in full-term children based on head computed tomography. Clin Pediatr (Phila) 53:1149-1157, 2014

23. Popich GA, Smith DW: Fontanels: range of normal size. J Pediatr 80:749-752, 1972

24. Shajari H, Rashidiranjbar N, Ashrafy M: Anterior fontanelle size in healthy Iranian neonates on the first day of life. Acta Med Iran 49:543-546, 2011

25. Tiansyah RA, Mangunatmadja I, Pulungan AB: Head circumference and anterior fontanel measurements in newborns. Paediatr Indones 52:145-151, 2012

26. Turğut M (ed): Research on Family Structure in Türkiye. Ankara: T.R. Ministry of Family and Social Policies, 2014

27. Uzukwu-Edeani CV, Ibeziako SN, Ikefuna AN, Uchendu UO: Normal anterior fontanelle sizes in newborn Igbo babies in south-eastern Nigeria. SAJCH 7:50-53, 2013

28. Weaver DD, Christian JC: Familial variation of head size and adjustment for parental head circumference. J Pediatr 96:990-994, 1980

29. WHO Multicentre Growth Reference Study Group: Assessment of differences in linear growth among populations in the WHO Multicentre Growth Reference Study. Acta Paediatr Suppl 450:56-65, 2006

30. Wintermeyer E, Ihle C, Ehnert S, Stöckle U, Ochs G, de Zwart P, et al: Crucial role of vitamin D in the musculoskeletal system. Nutrients 8:E319, 2016

31. Wu T, Li HQ: [Changes of anterior fontanel size in children aged 0 - 2 years.] Zhonghua Er Ke Za Zhi 50:493-497, 2012 (Chinese)

\section{Disclosures}

The authors report no conflict of interest concerning the materials or methods used in this study or the findings specified in this paper.

\section{Author Contributions}

Conception and design: Boran, Oğuz. Acquisition of data: Boran. Analysis and interpretation of data: all authors. Drafting the article: Boran, Furman. Critically revising the article: all authors. Reviewed submitted version of manuscript: all authors. Approved the final version of the manuscript on behalf of all authors: Boran. Statistical analysis: Furman, Sakarya. Study supervision: Oğuz, Furman.

\section{Correspondence}

Perran Boran: Marmara University, School of Medicine, Istanbul, Turkey.drperran@yahoo.com. 